\section{Increases in the prevalence of reduced visual acuity and myopia in Chinese children in Guangzhou over the past 20 years}

F Xiang ${ }^{1,2}, \mathrm{M} \mathrm{He}^{1,3}, \mathrm{Y} \mathrm{Zeng}^{1}$, J Mai ${ }^{4}, \mathrm{KA}_{\text {Rose }}^{5}$ and IG Morgan ${ }^{2}$

\begin{abstract}
Background/aims To estimate the prevalence of myopia based on reduced unaided visual acuity (VA) in Chinese school children over the past 20 years.

Methods Guangzhou school health authorities have measured VA on Grade 1-12 students from 1988 to 2007 annually, using a LogMAR tumbling E chart. VA is reported as Snellen categories: normal $(\mathrm{VA} \geq 6 / 6)$, mildly reduced $(6 / 9<\mathrm{VA}<6 / 6)$, moderately reduced $(6 / 18<\mathrm{VA} \leq$ $6 / 9)$, and severely reduced VA (VA $\leq 6 / 18$ ).

Results In 1988, over $80 \%$ of children in Grade 1 (age 6 years) and about 30\% in Grade 12 (age 17 years) had normal unaided VA. By 2007 , this dropped to only $60 \%$ in Grade 1 and about $10 \%$ in Grade 12. Conversely, the prevalence of moderately and severely reduced unaided VA increased from $6.2 \%$ in Grade 1 and $62.5 \%$ in Grade 12 in 1988 to $14.5 \%$ in Grade 1 and $84.11 \%$ in Grade 12 in 2007. This rate was unchanged from 2003 to 2007 at both the Grade 1 and Grade 12 levels.

Conclusions In Guangzhou, the prevalence of reduced unaided VA has increased markedly in the past 20 years, but has stabilized in the past few years. This increase may result from environmental changes, such as increased schooling intensity and urbanization.

Eye (2013) 27, 1353-1358; doi:10.1038/eye.2013.194; published online 6 September 2013
\end{abstract}

Keywords: epidemiology; myopia; longitudinal

\section{Introduction}

The prevalence of myopia in cities in East Asia is now very high in children, with around 80\% of students completing secondary school now myopic, and as much as $20 \%$ of them highly myopic. ${ }^{1-3}$ The prevalence of myopia in rural areas is slightly lower. ${ }^{3-8}$

The prevalence of myopia in East Asia was lower in the past. Wu and Edwards ${ }^{9}$ reported the prevalence of myopia over three generations, using non-cycloplegic autorefraction for the children and questionnaire data for the parents and grand parents. There was a progressive increase in the prevalence of myopia across the generations, and a declining risk associated with parental myopia. In addition, populationbased surveys of children from Taiwan using cycloplegic autorefraction ${ }^{3,10}$ demonstrated three trends-an increase in the prevalence of myopia, a decrease in the age of onset, and an increasing prevalence of high myopia. Similar trends are seen in Hong Kong ${ }^{11,12}$ and Japan. ${ }^{13}$ Collectively, these data demonstrate that the prevalence of myopia has increased substantially in East Asia over the past few decades. The speed of change suggests a role for environmental exposures, which can change more rapidly than gene pools. ${ }^{14}$

Analysis of the factors involved is complicated by the fact that the epidemic of myopia has already occurred, without the collection of longitudinal data on cycloplegic refractions and risk factors. Recent analyses ${ }^{15,16}$ have confirmed earlier suggestions ${ }^{17}$ that low unaided VA in children provides a proxy measure of myopia. The evidence for longitudinal change in Singapore is primarily based on VA measurements, ${ }^{18-20}$ but the high prevalence of myopia has been confirmed with
${ }^{1}$ State Key Laboratory of Ophthalmology, Zhongshan Ophthalmic Center, Sun Yat Sen University, Guangzhou, China

${ }^{2} \mathrm{ARC}$ Centre of Excellence in Vision Science and Visual Sciences Group, Research School of Biology, College of Medicine, Biology and Environment, Australian National University, Canberra, ACT, Australia

${ }^{3}$ Helen Keller International, New York, NY, USA

${ }^{4}$ Guangzhou Student's Health Care Institute of the Guangzhou City, Department of Education, Guangzhou, China

${ }^{5}$ Discipline of Orthoptics, Faculty of Health Sciences, University of Sydney, Lidcombe, NSW, Australia

Correspondence: M He, State Key Laboratory of Ophthalmology, Department of Preventive Ophthalmology, Zhongshan Ophthalmic Center, Sun Yat Sen University, Guangzhou 510060, China

Tel: +862087331109

E-mail: mingguang_he@ yahoo.com

Received: 12 October 2011 Accepted: 9 August 2013 Published online: 6 September 2013 
non-cycloplegic autorefraction. ${ }^{1}$ We have now applied this approach to a 20-year data set on VA in school children from Guangzhou.

\section{Materials and methods}

The Guangzhou Department of Education has measured unaided VA in a large sample of students in Guangzhou since 1988. All students in all grades in the selected schools were examined each year. The basic characteristics of the selected schools were shown in Table 1.

Unaided distance VA was measured for the right eye, then the left eye, with a retro-illuminated LogMAR chart with tumbling-E optotypes (Precision Vision, La Salle, IL, USA), with illumination of the examination rooms around $500 \mathrm{~lx}$. The child was asked to indicate the direction of the E optotype within $5 \mathrm{~s}$, and was observed closely for squinting. Measurements began at a distance of $5 \mathrm{~m}$, with the fourth line from the bottom $(6 / 6)$, using a staircase protocol, with four of the five optotypes identified taken as correct. The lowest line

Table 1 Enrolment number and gender ratio in examined schools, 1988-2007

\begin{tabular}{lcccccc}
\hline Year & $\begin{array}{c}\text { Number of } \\
\text { primary } \\
\text { schools }^{\text {a }}\end{array}$ & $\begin{array}{c}\text { Secondary } \\
\text { school no. }{ }^{\text {a }}\end{array}$ & $\begin{array}{c}\text { Grade } 1 \\
\text { students } \\
\text { no. }\end{array}$ & $\begin{array}{c}\text { Grade } 12 \\
\text { students } \\
\text { no. }\end{array}$ & $\begin{array}{c}\text { Males } \\
\text { Memales }\end{array}$ & Fem \\
\hline 1988 & 20 & 20 & 2268 & 4110 & 53.45 & 46.55 \\
1989 & 20 & 20 & 1560 & 2806 & 58.41 & 41.59 \\
1990 & 20 & 20 & 1754 & 5042 & 54.56 & 45.35 \\
1991 & 20 & 20 & 1664 & 4481 & 55.39 & 44.61 \\
1992 & 20 & 20 & 1877 & 5118 & 54.04 & 45.96 \\
1993 & 20 & 20 & 2061 & 2511 & 57.54 & 42.45 \\
1994 & 20 & 20 & 1701 & 5028 & 56.86 & 43.14 \\
1995 & 20 & 20 & 1607 & 4492 & 55.72 & 44.28 \\
1996 & 20 & 20 & 1768 & 4710 & 56.32 & 43.67 \\
1997 & 34 & 33 & 4207 & 2455 & 52.05 & 47.95 \\
1998 & 34 & 33 & 4467 & 4918 & 50.63 & 49.37 \\
1999 & 34 & 33 & 6141 & 5983 & 49.12 & 50.81 \\
2000 & 34 & 33 & 6356 & 5163 & 48.05 & 51.95 \\
2001 & 34 & 33 & 4167 & 9200 & 47.15 & 52.85 \\
2002 & 34 & 33 & 4237 & 7328 & 46.98 & 53.02 \\
2003 & 34 & 33 & 4805 & 8877 & 44.98 & 55.02 \\
2004 & 34 & 33 & 4655 & 10258 & 46.34 & 53.66 \\
2005 & 34 & 33 & 5223 & 10496 & 46.28 & 53.72 \\
2006 & 34 & 33 & 5010 & 12928 & 48.35 & 51.65 \\
2007 & 34 & 33 & 5067 & 15458 & 48.25 & 51.75 \\
\hline
\end{tabular}

${ }^{a}$ Before 1997, examinations were conducted in four districts of Guangzhou (Dongshan District, Yuexiu District, Haizhu District, and Liwan District) with five primary schools and five secondary schools, which integrate junior high school and senior high school, in each district. From 1997 on, another 13 primary schools and 14 secondary schools in another five districts (Tianhe District, Baiyun District, Huangpu District, Fangcun District, and Luogang District) were added. (Data derived from Guangzhou Yearbook, 1988-2007.) read successfully determined the VA for the eye. If the top line was not read, the child was advanced to 2.5 or $1 \mathrm{~m}$. VA examinations were carried out using a uniform protocol throughout the study years. Presenting and best-corrected VA were not measured.

Normal VA was defined as VA equal to or better than $6 / 6$. Mildly reduced VA was defined as VA better than $6 / 9$ and worse than $6 / 6$; moderately reduced as VA equal to or worse than $6 / 9$ and better than $6 / 18$, and severely reduced VA was defined as equal to or worse than 6/18. These categories should not be confused with WHO definitions of visual impairment, ${ }^{21}$ which are based on best-corrected VA of $<6 / 18$ in the best eye. Our category of moderately and severely reduced unaided VA includes the WHO categories of moderate and severe visual impairment and blindness, but is broader. Our categories of mildly and moderately reduced VA are not visual impairment under WHO definitions. Statistical analyses were performed with SPSS, 16.0 (SPSS Inc., Chicago, IL, USA). $\chi^{2}$ test was used to compare proportions among different grades and years. All statistical tests were two-sided, and $P<0.05$ was considered statistically significant.

\section{Results}

From 1988 to 2007, the enrolment rate in Grade 1 was over 99\%. Enrolment in Grade 7 rose from $92.36 \%$ in 1988 to over $99 \%$ from 1997. In Grade 10, enrolment increased from $71.63 \%$ in 1988 to $95.32 \%$ in 2007 . Boys comprised $53.5 \%$ students completing senior high schools in 1988, but only $48.3 \%$ in 2007 .

A very simple pattern is seen in the VA data for young students (Figure 1), where the population had predominantly normal VA, but with a decline in the percentage with normal VA in more recent cohorts, from $80.45 \%$ (95\% CI, 78.8-82.1) in 1988 to $62.21 \%$ (95\% CI, 60.9-63.5) in 2007. There was little severely reduced VA in any year, but the percentages of mildly reduced VA increased from $8.7 \%$ (95\% CI, 7.6-10.0) in 1988 to $22.4 \%$ (95\% CI, 21.7-23.6) in 2007, with an increase in the proportion of moderately reduced VA over the same period.

A very different pattern was seen in the Grade 12 (Figure 2). The proportion of severely reduced VA was already high at $42.4 \%(95 \%$ CI, 40.9-44.0) in 1988, but increased to $58.2 \%$ (95\% CI, 56.8-59.6) in 1998, reaching a maximum just above 70\% (95\% CI, 72.3-73.7) in 2007. Severely reduced unaided VA was the predominant state of Grade 12 students from around 1996. From 2003 on, there was little change in prevalence. Girls consistently showed lower proportions of normal VA and higher 


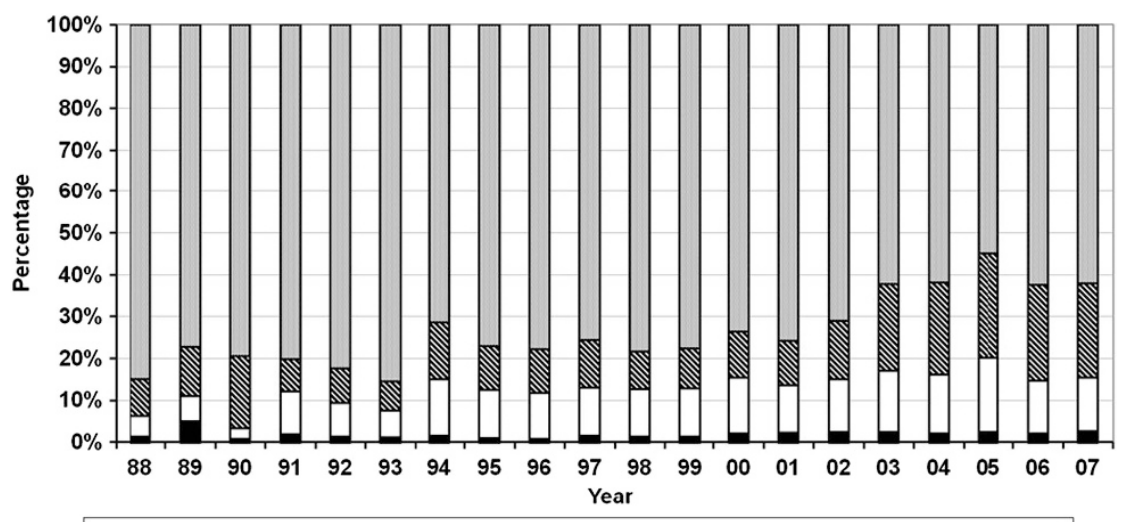

-Severely Reduced VA $\square$ Moderately Reduced VA sMildly Reduced VA 口Normal VA

Figure 1 Unaided visual acuity categories in Grade 1 from 1988 to 2007.

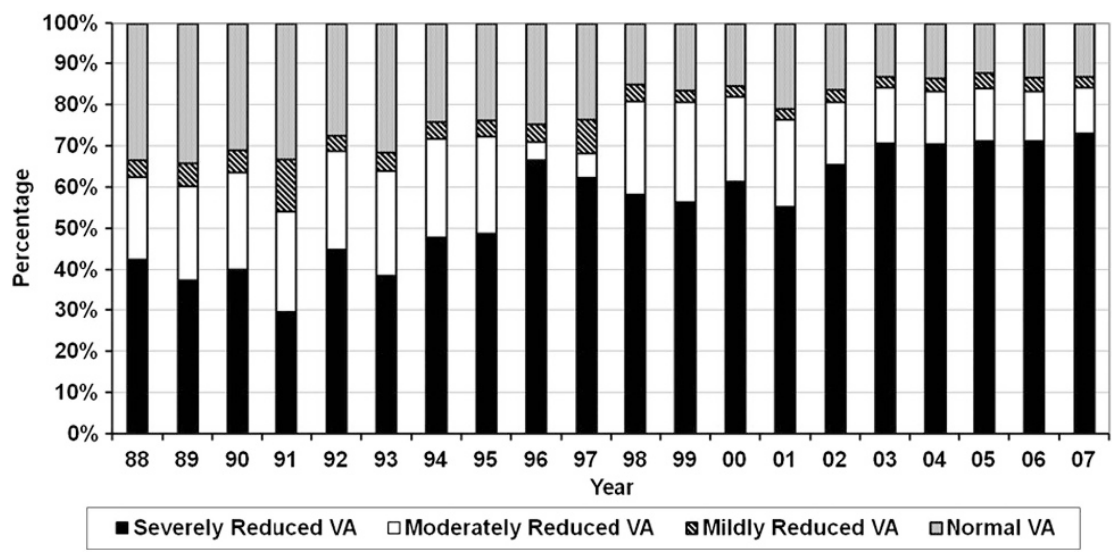

Figure 2 Unaided visual acuity categories in Grade 12 from 1988 to 2007.

proportions of moderately and severely reduced VA than boys ( $\chi^{2}$ test $P<0.05$ for each year).

How well the VA acuity data corresponded to the prevalence of myopia was assessed by comparing the levels of moderately and severely reduced VA from 2002 (taken as the proxy measure of myopia) to data on the prevalence of myopia determined by cycloplegic autorefraction in the population-based Guangzhou RESC study of the same year, which was conducted in Liwan District (Figure 3). The two curves are very similar with a correlation coefficient of 0.992 . For comparison, data from Taiwan for the 2000 survey are also plotted. The curves were similar in slope, but the Taiwan data showed slightly higher prevalence rates, probably due to the less stringent cutoff of $<-0.25 \mathrm{D}$ for myopia compared with the $\leq-0.5 \mathrm{D}$ cutoff used in the RESC studies.

In Taiwan, the prevalence of myopia has been over $70 \%$ in 18-year-old children since the first survey in 1983, reaching a plateau at around 85\% since 1995 (Figure 4). In contrast, the prevalence of moderately and severely reduced VA in Guangzhou was lower than the prevalence of myopia in Taiwan until about 2000, but has now reached a similar plateau.

\section{Discussion}

These data show that there has been a marked increase in the prevalence of severely and moderately reduced unaided VA in school children in Guangzhou over the past 20 years. In 2007, by the end of schooling, $<15 \%$ of children had normal VA compared with around 30\% in 1988. Over $70 \%$ had unaided VA $\leq 6 / 18$. Similar patterns of secular change were observed for both boys and girls, although girls showed consistently slightly more moderately and severely reduced unaided VA, consistent with the higher prevalence of myopia in girls. ${ }^{2}$

On the basis on the high correlation between the VA measurements from Guangzhou and the prevalence of myopia from the Guangzhou RESC study, ${ }^{2}$ and the validation of reduced VA as a predictor for myopia in the Singapore SCORM and Sydney Myopia studies, ${ }^{15,16}$ we suggest that the changes in VA over this 20-year 


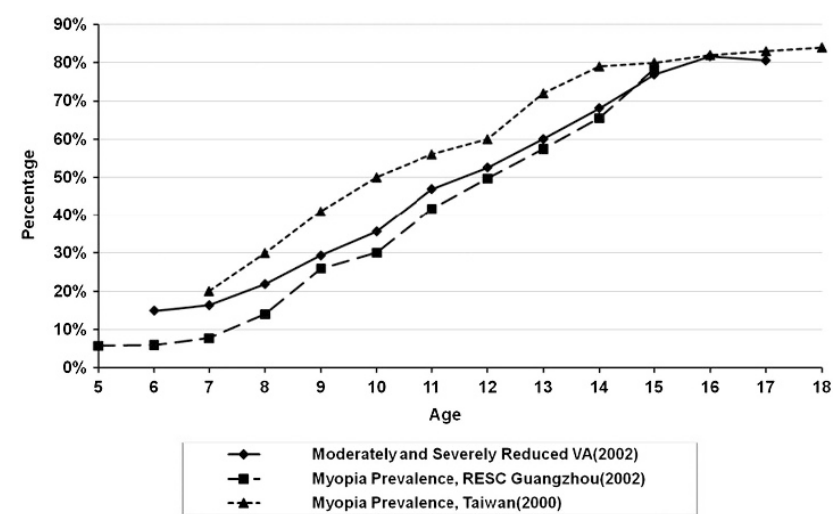

Figure 3 Comparison of the prevalence of moderately and severely reduced unaided VA from school testing for 2002 compared with the prevalence of myopia in the Guangzhou RESC data from $2002^{2}$ and in Taiwan in $2000^{3}$.

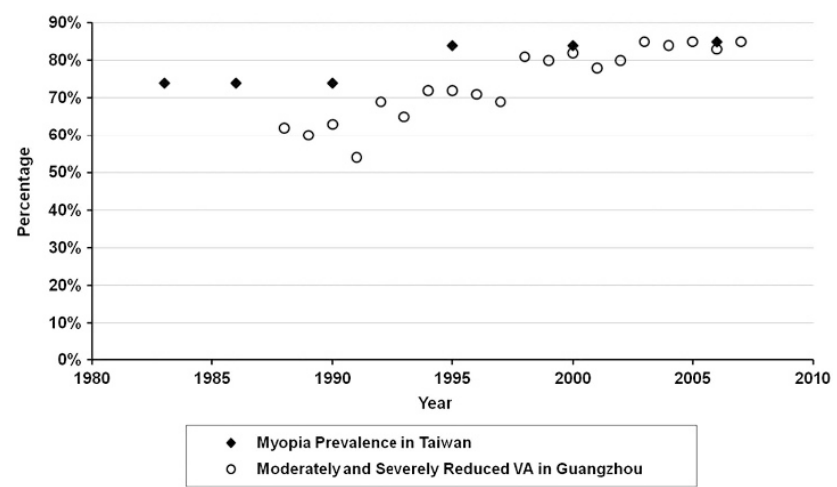

Figure 4 Comparison of secular changes in the prevalence of moderately and severely reduced VA in Guangzhou with the secular changes in the prevalence of myopia in Taiwan. ${ }^{3,10}$

period are largely due to an increasing prevalence of myopia. The characteristics of earlier onset, greater severity at the end of school, and current stabilization have previously been described in Taiwan for myopia. ${ }^{3}$

Participation in the school health survey in Guangzhou was compulsory, so participation was high. The areas from which the schools enrolled their students covered low, average, and high socioeconomic status areas.

(In 2000, the gross domestic product per capita was 25626 Chinese Renminbi for Guangzhou, whereas it was between 17935 and 31033 Chinese Renminbi for the areas where the schools enrolled their students. In 2007, the gross domestic product per capita was 71808 Chinese Renminbi for Guangzhou, whereas it was between 46576 and 470747 Chinese Renminbi for the areas where the schools enrolled their students.); thus, the schools were selected to give a representative sample of school students, although strict statistical randomization was not applied. School-based samples can give populationrepresentative results when enrolment rates are high, as they have been in Guangzhou, except in the case of rare disorders, which could lead to exclusion from mainstream schooling.

The high enrolment rates in Grade 1 from 1988, and Grade 7 from 1998 rules out major selection bias. The increased retention rate in senior high school to Grade 12 may mean that the Grade 12 students in the earlier years were more highly selected for high educational achievement, and hence that the population prevalence might be overestimated. Gender is a possible confounder, given the increase in the percentage of female students completing high school, but the gender differences are slight. Because the data compare large representative samples of students, comparison between years provides a valid estimate of secular changes.

The increase in prevalence of myopia may largely because of environmental changes in Guangzhou. However, another possibility is the change of genetic background of the children in Guangzhou, such as the selective migration of myopic parents, who might pass their myopia to their children, has produced the increase, particularly since the Guangzhou population rose from 
3490927 in 1988 to 6367621 in 2007 (Guangzhou Yearbook, 1988 and 2007). However, the relative risk of myopia in the children associated with parental myopia in Guangzhou is only 1.3, whereas most children in Guangzhou become myopic irrespective of the refractive status of their parents. ${ }^{22}$ We therefore conclude that the most plausible explanation of the secular changes in VA is the changing visual environment of children in Guangzhou.

The environmental factors involved have not been identified. Changes in education are a prime candidate, given the association between educational achievement and myopia. ${ }^{14}$ The oldest group (18 year olds examined in 1988) was born around 1970, and was not enrolled in the school system until after the Cultural Revolution. Uniform national university entry examinations were reintroduced in 1977, and a 9-year compulsory education policy promulgated in 1986. In 1999, institutions of higher learning increased enrolments, and the admission rate for those taking the university entrance examinations increased from $30 \%$ to nearly $50 \%$, resulting in higher educational aspirations for students and their parents.

Other factors have also changed. The degree of urbanization has increased in Guangzhou, with an increase in population density from 776 persons per $\mathrm{km}^{2}$ in 1988 to 1351 in 2007 (Guangzhou Yearbook, 1988 and 2007). Use of outdoor spaces for play may be important, given the substantial protective effect from the development of myopia of greater time spent outdoors. ${ }^{23,24}$ It is difficult to analyse these factors retrospectively. Other factors, such as nutrition and diet, have almost certainly changed over the past 20 years, but are also difficult to document retrospectively.

The data suggest that the prevalence of severely and moderately reduced VA has stabilized, at a high level, over the past few years. The prevalence of myopia in Taiwan appears to have stabilized at a similar level. The plateau was not reached until 2004 in Guangzhou, much later than in Taiwan. This might be explained by earlier economic development in Taiwan. The prevalence of self-reported myopia was about $20 \%$ in the parents of children (a cohort born even earlier) examined in Guangzhou 2002, ${ }^{22}$ suggesting that there had been a long-term increase in the prevalence of myopia.

Guangzhou is not representative of the whole of China, as it is the fourth largest city, but careful comparison of the VA data from Guangzhou with that from other cities and provinces may provide insights into the emergence of the current myopia epidemic. In addition, for less developed countries in the region, and indeed for other parts of the world at risk, ${ }^{25}$ population surveillance based on unaided VA measurements could provide early warning of an epidemic of myopia.

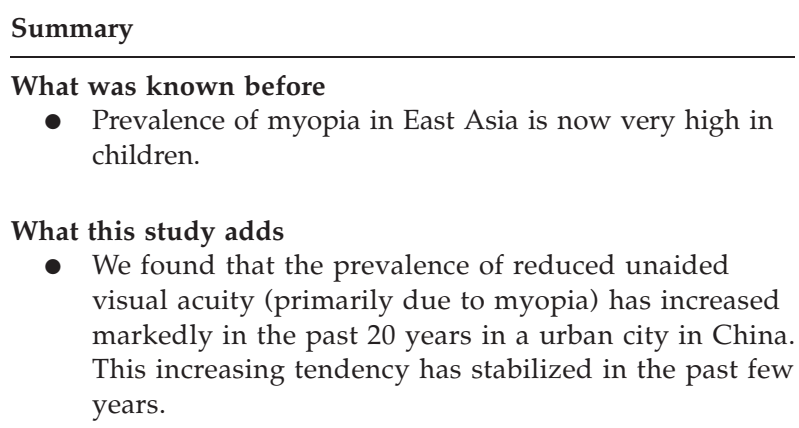

\section{Conflict of interest}

The authors declare no conflict of interest.

\section{Acknowledgements}

Michael and Susan Dell Foundation, Helen Keller International, and the Australian Research Council (ARC Centre of Excellence in Vision Science COE561903). The sponsors or funding organizations had no role in the design or conduct of this research.

\section{References}

1 Wu HM, Seet B, Yap EP, Saw SM, Lim TH, Chia KS. Does education explain ethnic differences in myopia prevalence? A population-based study of young adult males in Singapore. Optom Vis Sci 2001; 78: 234-239.

2 He M, Zeng J, Liu Y, Xu J, Pokharel GP, Ellwein LB. Refractive error and visual impairment in urban children in southern china. Invest Ophthalmol Vis Sci 2004; 45: 793-799.

3 Lin LL, Shih YF, Hsiao CK, Chen CJ. Prevalence of myopia in Taiwanese schoolchildren: 1983 to 2000. Ann Acad Med Singapore 2004; 33: 27-33.

4 Zhao J, Pan X, Sui R, Munoz SR, Sperduto RD, Ellwein LB. Refractive error study in children: results from Shunyi District, China. Am J Ophthalmol 2000; 129: 427-435.

5 He M, Huang W, Zheng Y, Huang L, Ellwein LB. Refractive error and visual impairment in school children in rural southern China. Ophthalmology 2007; 114: 374-382.

6 Congdon N, Wang Y, Song Y, Choi K, Zhang M, Zhou Z et al. Visual disability, visual function, and myopia among rural chinese secondary school children: the Xichang Pediatric Refractive Error Study (X-PRES)—report 1. Invest Ophthalmol Vis Sci 2008; 49: 2888-2894.

7 Qian YS, Chu RY, He JC, Sun XH, Zhou XT, Zhao NQ et al. Incidence of myopia in high school students with and without red-green color vision deficiency. Invest Ophthalmol Vis Sci 2009; 50: 1598-1605.

8 He M, Zheng Y, Xiang F. Prevalence of myopia in urban and rural children in mainland China. Optom Vis Sci 2009; 86: $40-44$.

9 Wu MM, Edwards MH. The effect of having myopic parents: an analysis of myopia in three generations. Optom Vis Sci 1999; 76: 387-392. 
10 Shih YF, Chiang TH, Lin LL. Lens thickness changes among schoolchildren in Taiwan. Invest Ophthalmol Vis Sci 2009; 50: 2637-2644.

11 Goh WS, Lam CS. Changes in refractive trends and optical components of Hong Kong Chinese aged 19-39 years. Ophthalmic Physiol Opt 1994; 14: 378-382.

12 Lam CS, Goh WS, Tang YK, Tsui KK, Wong WC, Man TC. Changes in refractive trends and optical components of Hong Kong Chinese aged over 40 years. Ophthalmic Physiol Opt 1994; 14: 383-388.

13 Matsumura $\mathrm{H}$, Hirai $\mathrm{H}$. Prevalence of myopia and refractive changes in students from 3 to 17 years of age. Surv Ophthalmol 1999; 44(Suppl 1): S109-S115.

14 Morgan I, Rose K. How genetic is school myopia? Prog Retin Eye Res 2005; 24: 1-38.

15 Tong L, Saw SM, Tan D, Chia KS, Chan WY, Carkeet A et al. Sensitivity and specificity of visual acuity screening for refractive errors in school children. Optom Vis Sci 2002; 79: 650-657.

16 Leone JF, Mitchell P, Morgan IG, Kifley A, Rose KA. Use of visual acuity to screen for significant refractive errors in adolescents: is it reliable? Arch Ophthalmol 2010; 128: 894-899.

17 Peckham CS, Gardiner PA, Goldstein H. Acquired myopia in 11-year-old children. BMJ 1977; 1: 542-545.
18 Chew SJ, Chia SC, Lee LK. The pattern of myopia in young Singaporean men. Singapore Med J 1988; 29: 201-211.

19 Tay MT, Au Eong KG, Ng CY, Lim MK. Myopia and educational attainment in 421,116 young Singaporean males. Ann Acad Med Singapore 1992; 21: 785-791.

20 Au Eong KG, Tay TH, Lim MK. Education and myopia in 110,236 young Singaporean males. Singapore Med J 1993; 34: $489-492$.

21 World Health Organization. International Statistical Classification of Diseases, Injuries and Causes of Death 10th Revision (ICD-10). WHO: Geneva, Switzerland, 1993.

22 Xiang F, He M, Morgan IG. The impact of parental myopia on myopia in Chinese Children: population-based evidence. Optom Vis Sci (E-pub) 2012; 89: 1487-1496.

23 Jones LA, Sinnott LT, Mutti DO, Mitchell GL, Moeschberger ML, Zadnik K. Parental history of myopia, sports and outdoor activities, and future myopia. Invest Ophthalmol Vis Sci 2007; 48: 3524-3532.

24 Rose KA, Morgan IG, Ip J, Kifley A, Huynh S, Smith W et al. Outdoor activity reduces the prevalence of myopia in children. Ophthalmology 2008; 115: 1279-1285.

25 Rose K, Smith W, Morgan I, Mitchell P. The increasing prevalence of myopia: implications for Australia. Clin Exp Ophthalmol 2001; 29: 116-120. 